\title{
Corrective feedbacks and their implications on learners' uptakes in academic speaking class
}

\author{
Didik Hartono $^{1 *}$ \\ ${ }^{1}$ Brawijaya University Jalan Veteran, Ketawanggede, Lowokwaru, Ketawanggede, Kec. Lowokwaru, Kota Malang, Jawa Timur 65145 \\ 1'didik_htono@yahoo.com \\ * corresponding author
}

\section{ARTICLE INFO}

\section{Article history}

Received April 04, 2018

Revised April 04, 2018

Accepted Mei 10, 2018

Keywords

Corrective Feedbacks

Categories of Errors

Explicit Correction

Students' Uptakes

Repetition

\begin{abstract}
This study attempts to investigate a study on corrective feedbacks and learners' uptakes in adult EFL classroom. The study was aimed at finding the types of corrective feedbacks were used by the academic speaking lecturer, the types of oral feedbacks were the most effective in the lecturer's opinion, the types of uptakes followed lecturer's corrective feedbacks, and the types of oral corrective feedbacks were mostly preferred by the students. The study employed a qualitative research design through a passive-participatory observation of patterns of error treatment in an adult EFL class. The research subjects were the lecturer and twenty seven students of the Academic Speaking Class, the English Department of Faculty of Culture Studies, Brawijaya University, Malang. The findings show that the lecturer applied explicit correction mostly (90\%), compared to another five types of corrective feedbacks. Moreover, the lecturer said that explicit correction was the most effective type of corrective feedbacks. Meanwhile, the findings also show that most student applied repetition type of uptake. On the other hand, most of the students answered that their preference of corrective feedback type was repetition corrective feedback.
\end{abstract}

This is an open access article under the CC-BY-SA license.

\section{Introduction}

Lecturers' habits dealing with students' spoken errors are varied, reflecting different attitudes they hold toward spoken errors. Some lecturers tend to correct all the errors while some tend to be tolerant and still some others do not correct at all. Learners can make errors because of some aspects, including interference, overgeneralization, markers of transitional competence, strategies of communication, assimilation and lecturer induced errors (Hasyim, 2002:42). Furthermore, Annet as cited in Chaudron (1998:133) states that "from the language lecturer point of view, the provision of feedback, or 'knowledge of results' is a major means by which to inform learners of the accuracy of both their formal target language production and their other classroom performance and knowledge". Sometimes, the lecturers view errors made by the students as an indication of unproductive teaching or as proof of failure, and they believed that when they occur they must be repaired by provision of correct forms, or that is to say, use of serious drilling and over teaching (Maicuzi and Lopez, $2000: 169$ ). 
When should errors be corrected? Chaudron (1988:136) states that "the general tendencies vary according to the instructional focus". Errors correction happens when the teaching and learning focus on form corrections. On the other hand, when focus is on the communicative competence lecturers tend to correct those errors which seem to obstruct communication. Which errors should be corrected? Chaudron (1988:140) also states that "errors which damage communication significantly, errors that have stigmatizing effects on the listener or the reader that should be corrected".

Moreover, in the language classroom the lecturer tends to correct the errors automatically, and it is equally important that delay in the correction would allow the learner a greater opportunity of self correction and would help the development of independent control processes, which are characteristic of the competence in communication of the mother language and which are considered to be necessary in the socialization of the second language. The routine correction on part of the lecturer actually runs the risk of making the learner depended on correction by others. Moreover, the over correction of an error by the lecturer as self correction of a problem of perception would add the risk of hurting the student's self esteem and would not imitate the acquisition process in the natural setting conditions.

This study therefore is intended to investigate meaningfulness of corrective feedback for error treatment, which later leads into the improvement of students' speaking skill in adult EFL classroom at the English Department, the Faculty of Culture Studies, Brawijaya University.

In addition, based on some observation done by the researchers, English lecturers seem to apply serious drilling and over teaching in treating their students' erroneous utterances, since they view errors as an indication of unproductive teaching or as proof of failure, and they believed that when they occur they must be repaired by provision of correct forms. Meanwhile, as university students, they should get an appropriate treatment and self-esteem, since self-esteem is one of the important factors in language learning. As (Lyster and Ranta, 1997) suggested that lecturers should be able to reflect on when determining their own policy for corrective feedback, including the capability in considering the context. Here, the lecturer should be able to understand first in what level their students is, and it will be easier for the lecturer to implement the corrective feedback type toward students' error, without decreasing students' self esteem. Considering those explanations, the writer thinks that it is necessary to conduct a study about adult of EFL students especially on student's error treatment on academic speaking class in the Faculty of Culture Studies Brawijaya University with four problems, in which to find 1) what types of oral corrective feedbacks given by the lecturer following learner's oral errors, 2) what types of uptakes following different types of corrective feedbacks, 3) what types of oral feedbacks are the most effective in the teacher's opinion, and 4) what types of oral feedbacks do most of the students prefer.

It is important to analyze learner's error in a proper view point, accordingly it is crucial to make a distinction between "mistake" and "error". Brown (2000) says that a "mistake" refers to a performance error in that it is a failure to utilize a known system correctly. Meanwhile an "error" is a noticeable deviation from the adult grammar of a native speaker, reflecting the interlanguage competence of the learner. In picking point of the explanation above, the recognition process is then followed by the error description process. James (1998) defines error analysis as "the process of determining the incidence, nature, causes, and consequences of unsuccessful language". Moreover, Dulay et.al. (1982:138) state that high-frequency errors should be the first errors lecturers should correct. Moreover, Chaudron (1988:136) categorized the range of errors from the strictly "linguistic including phonological, morphological, syntactic to subject matter content including factual and conceptual knowledge, and lexical items". Chaudron (1988:137) also specify some classification of errors into grammatical errors, including a) errors in the use of closed classes such as determiners, prepositions, and pronouns b) errors in grammatical gender (including wrong determiners and other noun and adjective agreements). c) error in pluralization, negation, question formation, and word order. Moreover, for lexical errors, including a) inaccurate, imprecise, or inappropriate choices of lexical items in open classes-namely, nouns, verbs, adverbs, and adjectives b) non target derivations of nouns, verbs, adverbs and adjectives, involving incorrect use of prefixes and suffixes. Furthermore, for phonological errors, including a) decoding errors as students read aloud b) Pronunciation of silent letters c) addition of other elements or omission of obligatory ones. 


\section{Corrective Feedbacks}

In language acquisition research, feedback generally refers to the listener's or reader's response given to the learner's speech or writing as it is stated by Dulay (1982). One type of feedback is correction, another is approval or "positive feedback," as some call it. Furthermore, Annet as cited in Chaudron (1998) states that from the language teacher's point of view, the provision of feedback, or "knowledge of results", is a major means by which to inform learners of the accuracy of both their formal target language production and their other classroom behavior and knowledge. From the learner's point of view, the use of feedback in repairing their utterances, and involvement in repairing their interlocutors' utterances, may constitute the most potent source of improvement in both target language development and other subject matter knowledge. In line with Dulay, Lyster and Ranta (1997) provide more detail definition of corrective feedbacks which are included in error treatment sequence as it were stated in Suzuki (2004:9):

1. Explicit correction: Clearly indicating that the student's utterance was incorrect, the teacher provides the correct form.

2. Recast: The teacher implicitly reformulates the student's error, or provides the correction without directly pointing out that the student's utterance was incorrect.

3. Clarification request: The teacher indicates that the message has not been understood or that the student's utterance included some kind of mistake and that a repetition or a reformulation is needed by using phrases like "Excuse me?"

4. Metalinguistic clues: The teacher poses questions like "Do we say it like that?" or provides comments or information related to the formation of the student's utterance without providing the correct form.

5. Elicitation: The teacher directly elicits the correct form from the student by asking questions.

6. Repetition: The teacher repeats the student's error and changes intonation to draw student's attention to it.

Meanwhile, Lyster and Ranta (1997) also provide corrective feedback flow which is considered as error treatment sequence as presented in figure 1

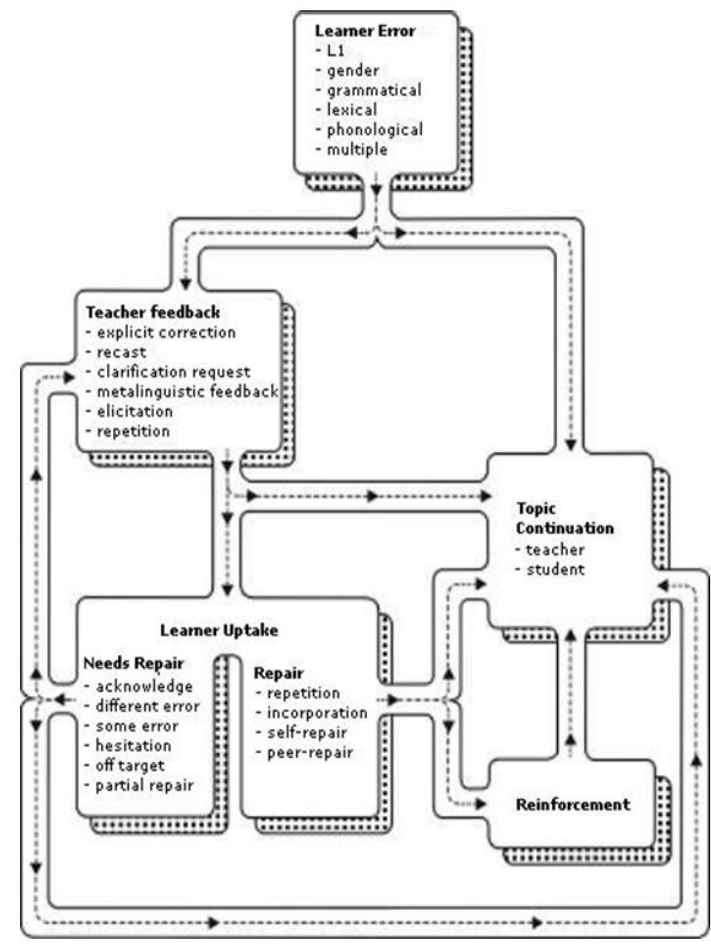

Fig. 1. Error Treatment Sequence 
Source: Lyster \& Ranta (1997). Corrective Feedback and Learner Uptake: Negotiation of form in communicative classrooms.

In the model presented in Figure 1, the figure is to be read as a flow chart presenting a series options that together compose an error treatment sequence.

\section{Uptakes or Learner Responses to Feedbacks}

Lyster and Ranta state that the notion of uptake has a very different meaning. In their research, the students' responses are called "uptake". In particular, uptake is deeply defined as "a student's utterance that immediately follows the teachers' feedback and that constitutes a reaction in some way to the teacher intention to draw attention to some aspect of the student initial utterance". In short, uptake is the students' trial to respond the teachers' corrective feedback. In the following of the previous statement about corrective feedback, Lyster and Ranta (1997) also exposed types of students' responses to teacher's corrective feedback. The data of their research reveals that two types of student uptake are most uptakes used by the student, they are uptake that produces an utterance still needing repair and uptake that produces a repair of the error on which the teacher's feedback focused. The definition of uptake for the present study will be also adapted from Lyster and Ranta's definition of uptake. That is, uptake is "a student's utterance that immediately follows the teacher's feedback and that constitutes a reaction in some way to the teacher's intention to draw attention to some aspect of the student's initial utterance" (Lyster \& Ranta, 1997). Lyster and Ranta categorized uptake moves into repair when the uptake move resulted in repair of an error, and needs-repair when an error was not repaired in the uptake move. In their study, no uptake was considered as the third category. No uptake referred to the case where teacher feedback was not responded to nor reacted to by the student at all. Lyster and Ranta distinguished four kinds of repair in their study: repetition, self-repair, peer-repair, and incorporation.

1. Repetition. A student repeats the correct form given in the teacher's feedback when the feedback includes the correct form.

2. Self-repair. This refers to a self-correction, produced by the student who made the initial error, in response to the teacher's feedback when the latter does not already provide the correct form.

3. Peer-repair. This refers to peer-correction provided by a student, other than the one who made the initial error, in response to the teacher's feedback. The nature of this uptake type is the same as self-repair.

4. The other type of uptake is needs-repair, which refers to a situation where the learner responds to the corrective feedback but the learner's utterance does not result in repairing the original erroneous utterance.

In Lyster and Ranta (1997), there were six types of needs-repair identified in their data: acknowledgement, same error, different error, off-target, hesitation, and partial repair.

1. Acknowledgement. The learner positively recognizes teacher's feedback, generally saying yes.

2. Same error. The learner gives uptake upon receiving feedback, but repeats the same error in his/her turn.

3. Different error. The learner does not correct nor repeat the error after the feedback, and makes a different error.

4. Off target. The learner responds to teacher feedback, but not to the targeted form in the feedback.

5. Partial repair. This refers to uptake that includes a correction of only part of the initial error. 


\section{Method}

The study is a descriptive qualitative with an observational study. In line with the design, the study collected most of the data by conducting a non-participant observation and focused on a particular place in a classroom. As it is stated by Bogdan and Biklen (1998) the descriptive qualitative study refers to the following criteria: 1) having one natural setting as the data sources 2) using the researcher as the key instrument, 3 ) focusing on the utterances or words as the analysis of the data rather than numbers, and 6) analyzing the data inductively.

Considering the above explanation, the study used classroom research design. The event investigated in this study was the teacher's error corrective feedbacks and the student's responds used in verbal interaction in Academic Speaking class on second semester students at Brawijaya University Malang 2011/2012 academic year. The study concerned with the utterances delivered by students, corrective feedbacks by the teacher in responding students' utterances, learner's uptake following different types of corrective feedbacks, and types of oral feedback that were the most effective according to the teacher's opinion, also types of oral feedback that were the most of the students prefer.

\section{Participants}

Subjects of the present study were the lecturer and the students of Academic Speaking class. The lecturer as the main subject chosen has these criteria:

1. She is a lecturer in English Department Brawijaya University since 2007.

2. She has an activity that makes the researcher have an opportunity to gain the data from the activities in her academic speaking class.

Considering those criterion, the teacher does not have problem with her competence or grammatical constructions.

Meanwhile, the students are in the second-semester of the English Department Brawijaya University, Malang. The researcher believes that the students are suitable with the topic of the research and their English is ideal in developing conscious awareness in understanding much of the spoken language.

\section{Instruments}

The researcher was the main instrument with the help of some other instruments during observations such as: field notes and voice recorder, interview, questionnaire, and documentation. All these instruments were documented from the first until the last observation. The researcher was passively involved in the process of subjects' activity.

\section{Data Collection}

The data needed for this research was collected through non-participant observation, recording, and interview. In acquiring the data, the following steps were taken. The first step was recording the needed data namely all utterances spoken by the teacher and the students in academic speaking class. The second step was transcribing the needed data namely all utterances spoken by the teacher and the students in academic speaking class. The third step was interviewing the lecturer to gain the data about the type of corrective feedback that the lecturer prefer and the most effective. The fourth step was distributing questionnaire to the students in order to identify the types of corrective feedback that students mostly prefer.

\section{Data Analysis}

In analyzing the data, the researcher used his observation sheets and the transcription gathered with the interview and the questionnaire as the result of the data collection. Therefore, first, the data need to be treated through a transcribing process, identifying the lecturer's and students' utterances and analyzing them. The second step was identifying the utterances containing the corrective feedbacks. The third step was coding utterances which contain corrective feedback delivered by the lecturer using serial numbers. The fourth step was classifying the utterances into types of error corrective feedbacks. The fifth step was classifying student's utterances as a response to lecturer's error corrective feedback. The sixth step was classifying the lecturer's dominant corrective feedback used. The seventh step was identifying the lecturer's opinion about the most effective corrective 
feedback based on the interview result. The eighth step was analyzing the result of the students' questionnaire to identify what types of corrective feedbacks that students mostly prefer.

Finally, the researcher checked the data, organized them, synthesized them, and searched for patterns of interaction and types of error corrective feedback and student's response.

\section{Findings and discussion}

The four sections provided by the researcher in in findings are the different types of corrective feedback used by the lecturer in responding to the students' erroneous utterances, the most effective corrective feedback according to the lecturer's opinion, the types of learner's uptake that immediately follows the lecturer's corrective feedbacks, and the types of corrective feedbacks that the students mostly prefer.

\section{The Types of Corrective Feedbacks Used by the Lecturer in Responding Learner's Errors}

The most suitable taxonomy of corrective feedback that was considered by the researcher related to the purpose of the study is Lyster and Ranta's (1997) taxonomy which developed a model to make a coding of error treatment sequences and make an identification of six different types of corrective feedbacks. Those corrective feedbacks were explicit correction, recasts, clarification requests, metalinguistic feedback, elicitation and repetition. In order to see better perspective data of the types of corrective feedbacks used by the lecturer in this study, it can be seen from the summary provided in table 1

Table 1. Types of Corrective Feedbacks Used by the Lecturer in Academic Speaking Class

\begin{tabular}{|c|c|c|c|c|c|c|c|c|c|c|c|}
\hline \multicolumn{2}{|r|}{ Types of CF } & S1 & S2 & S3 & S4 & S5 & S6 & S7 & S8 & S9 & $\mathbf{N}$ \\
\hline \multicolumn{2}{|r|}{ ECR } & 10 & 9 & 7 & 2 & - & - & 1 & 1 & - & 30 \\
\hline \multicolumn{2}{|r|}{$\mathrm{RCS}$} & - & - & - & - & - & - & - & - & - & - \\
\hline \multicolumn{2}{|r|}{ CRQ } & - & - & - & - & - & - & - & - & - & - \\
\hline \multicolumn{2}{|r|}{ ELC } & - & 1 & 1 & - & - & 1 & - & - & - & 3 \\
\hline \multicolumn{2}{|r|}{ MCL } & - & - & - & - & - & - & - & - & - & - \\
\hline \multicolumn{2}{|r|}{ RPT } & - & - & - & - & - & - & - & - & - & - \\
\hline \multicolumn{2}{|r|}{ Total } & & & & & & & & & & 33 \\
\hline 1. & $\mathrm{~S}$ & Student & & & & & & & & & \\
\hline 2. & $\mathrm{CF}$ & Correct & Feedl & & & & & & & & \\
\hline 3. & ECR & Explicit & rrecti & & & & & & & & \\
\hline 4. & $\mathrm{RCS}$ & Recast & & & & & & & & & \\
\hline 5. & CRQ & Clarific & $\mathrm{n} \operatorname{Rec}$ & & & & & & & & \\
\hline 6. & ELC & Elicitati & & & & & & & & & \\
\hline 7. & MCL & Metalin & tic C & & & & & & & & \\
\hline 8. & RPT & Repetiti & & & & & & & & & \\
\hline
\end{tabular}

It can be drawn from table 4.1 that the total number of corrective feedbacks given by the lecturer were thirty-three corrective feedbacks. Some of corrective feedbacks were used meanwhile some other corrective feedbacks were not used. Here, some more detailed explanation about table 4.1.

\section{The Most Effective Corrective Feedback Based on the Lecturer's Opinion}

According to Lyster (1998a:271), effective corrective feedback to be effective in eliciting student-generated repair or students-produced more output, which is considered to be effective for L2 acquisition.

In this study, to answer the second research question, the lecturer was asked some questions based on the interview guide. Here, based on the interview result, the lecturer answered that student's errors must be corrected right after they make an error. Furthermore, she explained that if she corrects the students' erroneous utterances after they finished their speech, it will be useless, 
since the students have already forgotten about their erroneous utterances or it can be said that delayed feedback toward erroneous utterances can allow the learner time to finish what the learner is trying to say, unfortunately the feedback may become less effective as the time between the error and treatment increases. Furthremore she explained that explicit correction was clear and easy to be understood by the student. It was truly supported by the analysis result achieved from the data on the field when the researcher did an observation, and it is also strengthened by the analysis result of the data transcription analysis.

\section{The Types of Uptakes Used by the Learners in Responding Lecturer's Corrective Feedback}

After corrective feedback given by the lecturer on a student's erroneous utterances, there may be a possibility for the student to react to the feedback in some way. In their error treatment sequence, Lyster and Ranta (1997) show the notion of uptake which is defined as a student response immediately following a corrective move provided by the lecturer.

Lyster and Ranta (1997) categorized uptake moves into "repair" when the uptake move resulted in repair of an error, and "needs-repair" when an error was not repaired in the uptake move. In their study, "no uptake" was considered as the third category. No uptake referred to the case where lecturer feedback was not responded to nor reacted to by the student at all. No uptake instances were considered worth analyzing since it would reveal what kind of feedback was not likely to lead to uptake. Lyster and Ranta distinguished four kinds of repair in their study: repetition, self-repair, peer-repair, and incorporation.

The other type of uptake is needs-repair, which refers to a situation where the learner responds to the corrective feedback but the learner's utterance does not result in repairing the original erroneous utterance. In Lyster and Ranta (1997), there were six types of needs-repair identified in their data: acknowledgement, same error, different error, off-target, hesitation, and partial repair.

The definitions of all types of uptakes are given along with some of their data found in this study. A better perspective data of the types of uptakes implemented by the student in this study, can be seen from the summary provided in table 2

Table 2. Types of Uptakes Used by the Learners in Following Lecturer's Corrective Feedbacks

\begin{tabular}{ccccccccccccc}
\hline CF & $\begin{array}{c}\text { Uptake } \\
\text { N }\end{array}$ & \multicolumn{4}{c}{ Repair } & \multicolumn{4}{c}{ Needs Repair } & & $\begin{array}{c}\text { No } \\
\text { Uptake }\end{array}$ \\
\hline & & RPT & SR & PR & ICP & ACK & SE & DE & OT & HT & PR & \\
ECR & 30 & 25 & - & - & - & - & 4 & 1 & - & - & - & - \\
ELC & 3 & - & 3 & - & - & - & - & - & - & - & - & - \\
MCL & - & - & - & - & - & - & - & - & - & - & - & - \\
RPT & - & - & - & - & - & - & - & - & - & - & - & - \\
Total N & 33 & - & - & - & - & - & - & - & - & - & - & - \\
\hline
\end{tabular}

\section{Types of Corrective Feedbacks:}

1. $\mathrm{CF}$ : Corrective Feedbacks

2. ECR : Explicit Correction : Explicit provision of the correct form

3. RCS : Recast : Lecturer's reformulation minus the error

4. CRQ : Clarification Request : Attempts the error with the rising tone

5. ELC : Elicitation : Elicit completion by strategically pausing

6. MCL : Metalinguistic Clue : Questions without providing the correct form

7. RPT : Repetition : Lecturer's repetition in adjusted intonation 


\section{Types of Uptakes}
Repair
1. RPT : Repetition
:Student repeats the correct form
2. SR : Self-Repair
: Student makes a self-correction
3. PR : Peer-Repair
: Correction by other student
4. ICP : Incorporation
: Longer utterance by the student

\section{Needs-Repair:}
1. ACK : Acknowledgement
: Responds feedback by saying yes
2. SE : Same Error
: Student repeats the same error
3. $\mathrm{DE}$
: Different Error
: Student makes a different error
4. OT
: Off-Target
5. HT
: Hesitation
6. PR
: Partial Repair
: Not to the targeted form in the feedback
: Students hesitate to respond to the feedback
: Correction of only part of the initial error

It can be drawn from table 2 that some types of uptakes were used meanwhile some other types of uptakes were not implemented by the students in this study.

The first type of uptakes used was repetition. Repetition can occur when a student repeats the correct form given in the lecturer's feedback when the feedback includes the correct form. In other words, the lecturer provides a reformulation of the student's ill-formed message. This reformulation is repeated by the student.

In this study the researcher found 25 repetition types of uptakes used by the students in responding to lecturer's corrective feedbacks. Related to corrective feedback types caused by errors as uttered above, some classification of errors are also found in this study, including grammatical error and phonological error. In line with that Chaudron (1998) specifies some classification of errors into grammatical errors, including a.) errors in the use of closed classes such as determiners, prepositions, and pronouns, b.) errors in grammatical gender (including wrong determiners and other noun and adjective agreements), c.) errors in pluralization, negation, question formation, and word order. Moreover, for lexical errors, including a.) inaccurate, imprecise, or inappropriate choices of lexical items in open classes-namely, nouns, verbs, adverbs, and adjectives b. nontarget derivations of nouns, verbs, adverbs and adjectives, involving incorrect use of prefixes and suffixes. Furthermore, for phonological errors, including a.) decoding errors as students read aloud, b.) pronunciation of silent letters, c.) addition of other elements or omission of obligatory ones. Unfortunately, in this study the researcher cannot find any examples of lexical errors done by the students. These are the 24 rigid explanations about repetition as an uptake move done by the students, with "L" that represents lecturer, and "S" that represents student, and numbers that represent of the students' order in delivering their presentation, and " $U$ " as an uptake move done by the student in following lecturer's corrective feedback:

Moreover, there are two types of errors detected from the data from this study. These were grammatical and phonological error. Table 3 shows the percentage of each corrective feedback toward the whole types of corrective feedbacks.

Table 3. The Percentage of Each Corrective Feedback Type

\begin{tabular}{ccccccc}
\hline $\begin{array}{c}\mathbf{N} \\
\text { (Total } \\
\text { 33) }\end{array}$ & $\begin{array}{c}\text { Explicit } \\
\text { Correction }\end{array}$ & Recast & $\begin{array}{c}\text { Clarification } \\
\text { Request }\end{array}$ & $\begin{array}{c}\text { Metalinguistic } \\
\text { Clues }\end{array}$ & Elicitation & Repetition \\
\hline$\%$ & 90 & - & - & - & 10 & - \\
\hline
\end{tabular}

The different percentage of feedback types are shown in Table 3 above. From those six different types of error corrective feedbacks, the explicit correction was the largest category $(90 \%)$, followed 
by elicitation (10\%). There was a notification that the two most widely used feedback moves, namely explicit correction and elicitation. These two types account for $100 \%$ of all the feedbacks.

The total number of corrective feedback moves in the data was thirty three. Furthermore, there were some types of uptake followed the lecturer's corrective feedbacks as shown in table 4.4.

Table 4. $\quad$ Uptake Following Lecturer's Feedback

\begin{tabular}{|c|c|c|c|c|c|c|}
\hline & \multicolumn{2}{|c|}{ Uptake } & \multicolumn{2}{|c|}{ Repair } & \multicolumn{2}{|c|}{ Needs repair } \\
\hline & $\mathbf{N}$ & $\%$ & $\mathbf{N}$ & $\begin{array}{c}\% \text { of } \\
\text { feedback } \\
\text { type }\end{array}$ & $\mathbf{N}$ & $\begin{array}{c}\% \text { of } \\
\text { feedback type }\end{array}$ \\
\hline Explicit Correction & 30 & 90 & 25 & 75 & 5 & 16 \\
\hline Recast & - & - & - & - & - & - \\
\hline Clarification Request & - & - & - & - & - & - \\
\hline Metalinguistic Clues & - & - & - & - & - & - \\
\hline Elicitation & 3 & 10 & 3 & 9 & - & - \\
\hline Repetition & - & - & - & - & - & - \\
\hline Total $(\mathrm{N}=33)$ & & & & & & \\
\hline
\end{tabular}

In this study, the most preferred of feedback that lead to uptake were explicit correction and elicitation. However, most of the uptake following explicit correction feedback technique $(90 \%)$ was categorized under repair, due to the students' tendency to repeat the correct utterance after the explicit correction by the lecturer.

In this study, in particular, high rates of uptake applied were explicit correction and elicitation $(90 \%$ and $10 \%)$. From those two types of corrective feedbacks, elicitation was the type which effectively prompts a student reaction and invite students to self-correct. All of the elicitation moves $(100 \%)$ resulted in repair.

\section{The Student's Most Preferred Types of Corrective Feedbacks}

These are the result of calculating the answer from questionnaire given to the student's. From total voters who have made their choice toward questions in questionnaire, it can be concluded that the most preferred type of corrective feedback is repetition type of feedback with 59.2 percent or 26 voters of 33 voters.

\section{Discussion}

The four sections provided in findings are discussion on the types of corrective feedbacks used by the lecturer in responding learner's errors, discussion on the most effective corrective feedback based on the lecturer's opinion, discussion on the types of uptakes used by the learners in responding lecturer's corrective feedback, and discussion on the student's most preferred types of corrective feedbacks.

\section{The Types of Corrective Feedbacks Used by the Lecturer in Responding Learner's Errors}

It can be drawn from Table 1 about types of corrective feedbacks used by the lecturer in academic speaking class. It shows that the lecturer applied explicit correction mostly, compared to another five types of corrective feedbacks including recast, clarification request, metalinguistic clues, elicitation, and repetition. As the lecturer provides the correct form, she clearly indicates that what the student had said was incorrect. On occasion, the wrong form is identified along with providing a correct form in the lecturer's turn.

Furthermore, in answering the first research question (What types of oral corrective feedbacks are given by the lecturer that follow student's oral errors?), the findings show that some types of errors including grammatical and phonological errors invited explicit correction more than any other type of corrective feedbacks, and that all two types used by the lecturer in correcting her student's erroneous utterances, elicitation has the second position used by the lecturer.

On the other hand, all of the corrective feedback types led to uptake. And, as stated previously that the type of corrective feedback that led to repair the most was explicit correction $(90 \%)$ with elicitation (10\%) being the second most used feedback that resulted in repair. 
Additionally, from the result of the questionnaire given to the lecturer, some insights of her interest in giving a corrective feedback are revealed. The first is the students' errors must be treated and corrected seriously, otherwise they will not realize that their utterances are wrong since there is no corrective feedback from their lecturer and they continue to use their wrong utterances. The second is the best time to make correction toward students' error is right after they make an error. According to the lecturer, if she treats the students' mistake after her students finished her speech, it will be useless, students will forget their errors. Of course, she must make an agreement with the student first about this, to maintain her students' self esteem in learning English.

In the contrary of her statement above, Chaudron (1998:136) argues that the timing in giving error correction should vary according to the instructional focus. Error correction happens when the teaching and learning focus on form corrections. On the other hand, when focus is on the communicative competence lecturers tend to correct those errors which seem to obstruct and damage communication significantly.

The third is two kind of corrective feedbacks were implemented by the lecturer in this study, respectively explicit correction with $90 \%$ and elicitation with $10 \%$ of total corrective feedbacks. And the reason of doing explicit correction is this type of corrective feedback is clear and easy to be understood by the student. On the other hand, the reason of doing elicitation is this type of corrective feedback is able to motivate them to find the correct form of the error and do a self-repair.

\section{Discussion on the Most Effective Corrective Feedback Based on the Lecturer's Opinion}

It can be drawn from Table 2 that some types of uptakes were used meanwhile some other types of uptakes were not used. The first type of uptakes used is repetition. Repetition can occurs when a student repeats the correct form given in the lecturer's feedback when the feedback includes the correct form. In other words, the lecturer provides a reformulation of the student's ill-formed message. This reformulation is repeated by the student.

In this study the researcher found 24 repetition type of uptakes used by the students in responding lecturer's corrective feedbacks, and it means that $90 \%$ of the total corrective feedbacks were explicit corrections. In the present study, the lecturer only implemented two types of corrective feedbacks with explicit correction as the dominant one. In this type of corrective feedback the lecturer provides the correct form of her students' erroneous utterances, and she clearly indicates that what the student had said was incorrect. On occasion, the wrong form is identified along with providing a correct form in the lecturer's turn. And from the Table 3 it can be revealed that all types following explicit corrective feedback types were repetition uptakes. Here, there is no opportunity given to the students to find their own correct utterances after given corrective feedback. On the other hand, only ten percent of lecturer's corrective feedback types were elicitation, which enable students to make a self-repair. This type of corrective feedback refers to techniques that lecturers use to directly elicit the correct form from the student. One technique is that lecturers elicit completion of their own utterance by strategically pausing to allow students to fill in the blank as it were. The other technique is that lecturers use questions to elicit correct forms. Either way, lecturers do not provide correct forms in their turn Lyster and Ranta (1997).

Furthermore, Horwitz (1988), as cited in Park (2010:9), argues that students' belief about language learning should be understood by the lecturers in order to foster effective learning strategies to avoid disappointment caused by a mismatch between students' expectations and the realities they encounter in the classroom. This disappointment can impede students' language acquisition.

\section{Discussion on the Types of Uptakes Used by the Learners in Responding Lecturer's Corrective Feedback}

It can be described from the result of the interview that the lecturer agreed with the students' spoken errors need to be corrected. Related with that, based on the questionnaire result, eighty-five percent of the students agreed with the statement "As soon as errors are made even if it interrupts my speaking." To sum up, those two opinions between lecturer's and students' preference about time to give error correction are in the same position which is right after errors are made. For the most effective type of corrective feedback, the lecturer highly valued explicit corrective feedback over another types of corrective feedbacks since this type of corrective feedback directly points out 
the location of the error that can increase the chance of modification and accelerate learning. The lecturers also favored elicitation in the second position that can help students to produce target-like forms and do their self-repair.

\section{Discussion on the Student's Most Preferred Types of Corrective Feedbacks}

For the lecturer's and students' preference of corrective feedback type, some explanations are revealed from the finding in the previous explanation. Based on the questionnaire results, the students' preference is repetition type of corrective feedback. Meanwhile the lecturer's preference is explicit correction. From the above explanation, the finding reveals that students want to get a repetition corrective feedback more than other types of corrective feedbacks. This findings provide the fact that the lecturer in providing corrective feedback should consider her students' preference for the type of corrective feedback in correcting their erroneous utterances, in order to achieve the goal of the course.

\section{Conclusion}

This part presents the conclusions It deals with conclusions concerning the research questions and results of the study discussed in the previous chapter. It can be drawn from the findings of this current study that the 1) types of corrective feedbacks used by the lecturer in academic speaking class is explicit correction mostly, compared to another five types of corrective feedbacks which are recast, clarification request, metalinguistic clues, elicitation, and repetition 2) Meanwhile, elicitation has the second position used by the lecturer in correcting her students' erroneous utterances. 3) Furthermore all of the corrective feedback types led to uptake. 4) And, as stated in previous explanation that the type of corrective feedback that led to repair the mostly was explicit correction $(90 \%)$, with elicitation (10\%) being the second most used feedback that resulted in repair.

\section{References}

Bogdan, R.G., \& Biklen, S.K. 1998. Qualitative Research for Education: An Introduction Theory and Method. Boston: Ally and Bacon Press.

Brown, H. D. 1993. Principles of Language Learning and Teaching. Englewood Cliffs: San Francisco. Prentice-Hall Press.

Brown, H. D. 2000. Principles of Language Learning and Teaching. San Francisco. Longman Press.

Chaudron, C. 1988. Second Language Classrooms. Research on Teaching and Learning. Cambridge. Cambridge University Press.

Dulay H., Burt M., and Krashen S. 1982. Language Two. New York. Oxford. Oxford University Press.

Ellis, R. 1994. The Study of Second Language Acquisition. Oxford. Oxford University Press.

Ellis, R. 1997. Second Language Acquisition. Oxford. Oxford University Press.

Hasyim, A. 2002. Error Analysis in the Teaching of English. Journal of Kata. 2002, Volume 4 (1).

James, C. 1998. Errors in Language Learning and Use. Exploring Error Analysis. New York. Addison Wesley Longman Press.

Lyster, R., and Ranta, L. (1997). Corrective feedback and learner uptake: Negotiation of form in communicative classrooms. Cambridge. Cambridge University Press.

Lyster, R. 1998a. Negotiation of Form, Recasts, and Explicit Correction in Relation to Error Types and Learner Repair in Immersion Classrooms. Cambridge. McGill University

Suzuki, M. 2010. Corrective Feedback and Learner Uptake in Adult ESL Classrooms. Working Papers in TESOL \& Applied Linguistics Journal. 2010. Volume 4(2) 